\title{
Can ABCF2 protein expression predict the prognosis of uterine cancer?
}

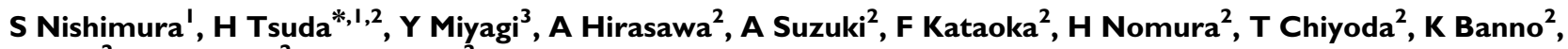 \\ T Fujii $^{2}, \mathbf{N}$ Susumu ${ }^{2}$ and D Aoki ${ }^{2}$
}

'Department of Obstetrics and Gynecology, Osaka City General Hospital, Osaka, Japan; ${ }^{2}$ Department of Obstetrics and Gynecology, Keio University School of Medicine, Tokyo Japan; ${ }^{3}$ Department of Obstetrics and Gynecology, Okayama Ohfuku Clinic, Okayama, Japan

\begin{abstract}
Uterine cervical and endometrial cancers are common malignant solid neoplasms for which there are no useful prognostic markers. In this study, we evaluate the relationship between ATP-binding cassette superfamily F2 (ABCF2) expression and clinical factors including clinical stage, histologic type, grade and prognosis in uterine cervical and endometrial cancer. Two hundred and sixty seven cervical and 103 endometrial cancers were studied. ATP-binding cassette superfamily F2 cytoplasmic expression was detected by immunohistochemical staining and scored as positive or negative. Among cervical cancer cases, I 49 (55.8\%) expressed ABCF2. The overall survival was longer in ABCF2-negative than ABCF2-positive cases $(P=0.0069)$. Statistically significant prognostic factors for survival were ABCF2 positivity (risk ratio $(r r)=1.437)$, old age $(r r=1.550)$ and advanced stage $(r r=2.577)$. ATP-binding cassette superfamily F2 positivity was an independent prognostic factor by multivariate proportional hazard test $(P=0.0002)$. Among endometrial cancer cases, 72 (69.9\%) were cytoplasmic ABCF2 positive. However, there was no significant relationship between ABCF2 expression and age, clinical stage, histologic type, histologic grade, oestrogen receptor status or prognosis. ATP-binding cassette superfamily F2 expression may be a useful prognostic marker in cervical but not endometrial cancer. The role of ABCF2 protein may differ depending on the type of cancer.
\end{abstract}

British Journal of Cancer (2008) 99, I65 I - 1655. doi:I0.1038/sj.bjc.6604734 www.bjcancer.com

(c) 2008 Cancer Research UK

Keywords: $A B C$ transporter; cervical cancer; endometrial cancer; prognosis

Carcinoma of the uterine cervix is a common malignant solid neoplasm in Japanese women and its incidence in young women is increasing (Ioka et al, 2003; The Japan Cancer Surveillance Research Group, in press). The prognosis is influenced by health condition such as anaemia, hypertension, neutrophil count or diabetes, clinical stage including tumour volume, endometrial extension and lymph node involvement (Stehman et al, 2000). Several studies have assessed the role of human papillomavirus (HPV) and HPV type on outcome with conflicting results (Randall et al, 2005). Proliferation, apoptosis and other cellular characteristics have been suggested to correlate with clinical outcome although these associations have not been conclusively established (Riou et al, 1988; Sagae et al, 1989; Koulos et al, 1993; Tsang et al, 1995; Gaffney et al, 2003). Several genes that control cell growth and differentiation have been investigated as prognostic markers in cervical cancer, but as yet no clearly useful marker has been identified.

Endometrial cancer is also increasing in Japan (Ioka et al, 2003; The Japan Cancer Surveillance Research Group, in press) and the prognosis is reported to be influenced by histologic type, grade and clinical stage (Trope et al, 2005). Mutations of p53 gene, HER-2/ neu amplification and reduced E-cadherin expression have been reported to be poor prognostic indicators but their importance remains to be established (Hamel et al, 1996; Lundgren et al, 2002; Moreno-Bueno et al, 2002). New biomarkers able to predict the

*Correspondence: Dr H Tsuda; E-mail: htsud@sc.itc.keio.ac.jp

Revised 13 August 2008; accepted 23 September 2008 prognosis of uterine cervical and endometrial cancers are therefore urgently needed and would be extremely useful.

We have produced an antibody to the ATP-binding cassette superfamily $F(A B C F 2)$ protein and demonstrated that ABCF2 protein expression is higher in clear cell adenocarcinoma (CCC) of the ovary than in other histologic types and may predict chemotherapy response and prognosis (Tsuda et al, 2005a; Nishimura et al, 2007). ATP-binding cassette superfamily F2 is a member of the GCN20 subfamily of the ABC transporter superfamily (Vasquez de Aldana et al, 1995; Allikmets et al, 1996; Kerr, 2004). Yasui et al reported that the ABCF2 gene is amplified in a chemoresistant ovarian cancer cell line (t24/cDDp10), with chromosome gain at 7q34-36 (Yasui et al, 2005). In this study, we evaluate the relationship between ABCF2 expression and clinical stage, histologic type, histologic grade and prognosis in uterine cervical and endometrial cancer.

\section{MATERIALS AND METHODS}

\section{Clinical samples}

Between February 1994 and December 2004, 385 samples (267 invasive cervical cancers, 103 endometrial cancer, 5 proliferative endometrium, 5 secretary phase endometrium and 5 normal cervical epithelium) of paraffin-embedded tissues were collected at Osaka City General Hospital. All patient-derived paraffin sections were archived under the protocols approved by the institutional review board (IRB) of Osaka City General Hospital. 

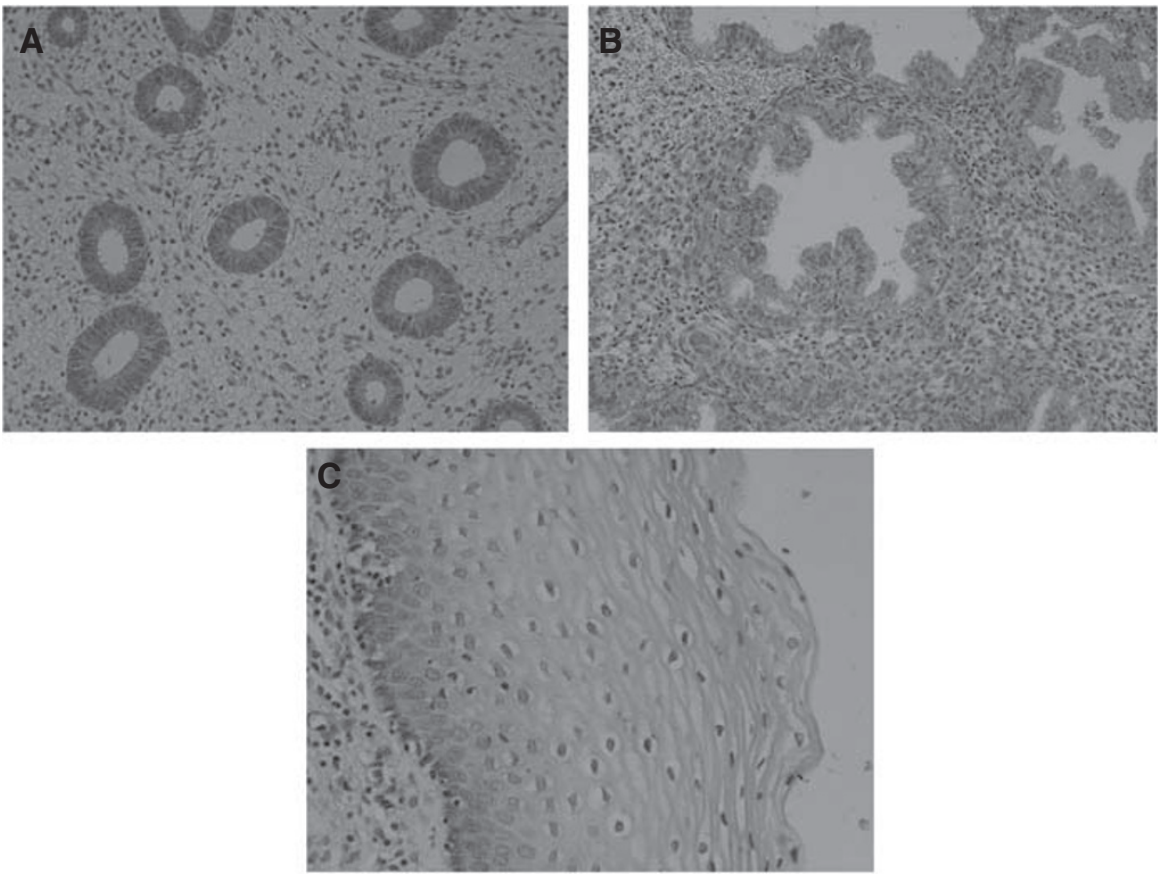

Figure I (A) ATP-binding cassette superfamily F2-positive proliferative endometrium. (B) ATP-binding cassette superfamily F2-positive secretary endometrium. (C) ATP-binding cassette superfamily F2-negative cervical epithelium.

Table I ATP-binding cassette superfamily F2 (ABCF2) expression in cervical cancer

\begin{tabular}{llc}
\hline Parameter & ABCF2 expression & P-value \\
\hline Age & & \\
$\quad$ Median & $50.4 \%(7|/| 4 \mid)$ & 0.065 \\
$\quad$ Median & $61.9 \%(78 / \mid 26)$ & \\
FIGO stage & & \\
I+II & $50.7 \%(|08 / 2| 3)$ & 0.001 \\
III+IV & $75.9 \%(4 \mid / 54)$ & \\
Histologic type & & \\
$\quad$ Squamous & & \\
Non-squamous & $54.9 \%(\mid 24 / 226)$ & \\
\hline
\end{tabular}

Of 267 invasive cervical cancers, 146 were stage I, 67 stage II, 33 stage III and 21 stage IV. Two hundred and twenty six were squamous cell carcinoma, 26 adenocarcinoma and 15 adenosquamous cell carcinoma. Among the 103 endometrial cancers, 63 were stage I, 6 stage II, 31 stage III and 3 stage IV. Eighty-six were endometrioid adenocarcinoma, six adenoachanthoma, five adenosquamous carcinoma, four CCC and two undifferentiated carcinoma. Forty-four were grade1, 42 grade 2 and 13 grade 3 . The median ages of cervical and endometrial cancer patients were 53 (range 22-92) and 55 years (range $32-77$ ), respectively. Histologic diagnosis was confirmed by microscopic examination of hematoxylin-and-eosin-stained sections according to the International Federation of Gynecology and Obstetrics (FIGO) system.

As primary therapy 70 cervical cancer patients received radiation therapy and 197 surgery. After primary therapy, 55 had adjuvant radiotherapy and 10 platinum based adjuvant chemotherapy. Twenty-nine patients received platinum-based neoadjuvant chemotherapy. All endometrial cancer patients were first
Table 2 ATP-binding cassette superfamily F2 (ABCF2) expression in endometrial cancer

\begin{tabular}{|c|c|c|}
\hline Parameter & ABCF2 expression & $P$-value \\
\hline \multicolumn{3}{|l|}{ Age } \\
\hline $\begin{array}{l}<\text { Median } \\
>\text { Median }\end{array}$ & $\begin{array}{l}68.6 \%(35 / 51) \\
71.2 \%(37 / 52)\end{array}$ & 0.832 \\
\hline \multicolumn{3}{|l|}{ FIGO stage } \\
\hline $1+\|$ & $68.1 \%(47 / 69)$ & 0.652 \\
\hline III+IV & $73.5 \%(25 / 34)$ & \\
\hline \multicolumn{3}{|l|}{ Histologic type } \\
\hline Endometrioid & $69.6 \%(64 / 92)$ & 0.999 \\
\hline Non-endometrioid & $72.7 \%(8 / I I)$ & \\
\hline \multicolumn{3}{|l|}{ Histologic grade } \\
\hline $1+2$ & $68.6 \%(59 / 86)$ & 0.773 \\
\hline 3 & $76.5 \%(13 / 17)$ & \\
\hline \multicolumn{3}{|l|}{ Estrogen receptor } \\
\hline Positive & $71.2 \%(47 / 66)$ & 0.384 \\
\hline Negative & $58.8 \%(10 / 17)$ & \\
\hline
\end{tabular}

treated surgerically. Post-operatively 51 received platinum-based adjuvant chemotherapy and 2 adjuvant radiotherapy.

\section{Immunohistochemistry}

ATP-binding cassette superfamily F2 protein expression was detected immunohistochemically using a polyclonal anti-ABCF2 antibody generated by immunising rabbits with a purified fulllength ABCF2 fusion protein. The specificity of the antibody was determined by western blot and immunohistochemical analyses on human embryonic kidney cells (293T) transfected with an 
expression vector pcDNA3.1 or with the vector containing either a full-length ABCF2 coding sequence or a full-length ABCF2 coding sequence with a myc and a His tag (Tsuda et al, 2005b).

Histological sections ( $4 \mu \mathrm{m})$ were affixed to glass slides, dewaxed and rehydrated. The sections were incubated in $3 \%$ hydrogen peroxide for $10 \mathrm{~min}$ at room temperature to quench endogeneous peroxidase activity and incubated with the ABCF2 antibody $(1: 5000)$ at $4^{\circ} \mathrm{C}$ overnight. After rinsing, the sections were incubated for 30 min with rabbit EnVision + Peroxidase (DAKO, Glostrup, Denmark). Peroxidase activity was visualised by applying diaminobenzidine chromogen containing $0.05 \%$ hydrogen peroxide for $2-10 \mathrm{~min}$ at room temperature, and the sections were counterstained with hematoxylin. Slides were read by two independent pathologists, who were blinded to the clinical background of the patients. Evaluation of ABCF2 positives were reported previously (Tsuda et al, 2005a; Nishimura et al, 2007). ATP-binding cassette superfamily F2 protein is a member of ABC transporter superfamily and the GCN20 subfamily (Vasquez de Aldana et al, 1995) and we demonstrated that ABCF2 protein is predominantly located in the cytoplasm of cells (Tsuda et al, 2005a; Nishimura et al, 2007). Thus, in this study, we judged the positivities of this protein based on the cytoplasmic staining into either positive or negative.
Slides from epithelial ovarian cancer patients confirmed to be $\mathrm{ABCF} 2$ positive or negative in previous reports that were used as controls (Tsuda et al, 2005a; Nishimura et al, 2007).

\section{Statistical analysis}

The relationship between $\mathrm{ABCF} 2$ expression and age, clinical stage and histologic type were analysed by $\chi^{2}$ test. Patients were categorised as young or old ( $>53$ years) and early or advanced (not less than stage IIIa) disease. Factors influencing 5-year survival were analysed by both Cox's proportional hazard test and the Kaplan-Meier test. After investigation of the multicollinearity of these factors, multivariate Cox's proportional hazard test was applied. A $P$-value of $<0.05$ was considered statistically significant.

\section{RESULTS}

\section{ABCF2 expression}

In one of seven proliferative endometriums and six of eight secretary endometriums, ABCF2 cytoplasmic weakly immunostaining was detected; however, in normal cervical epithelium, no $\mathrm{ABCF} 2$ immunostaining was detected (Figure 1A-C). Among
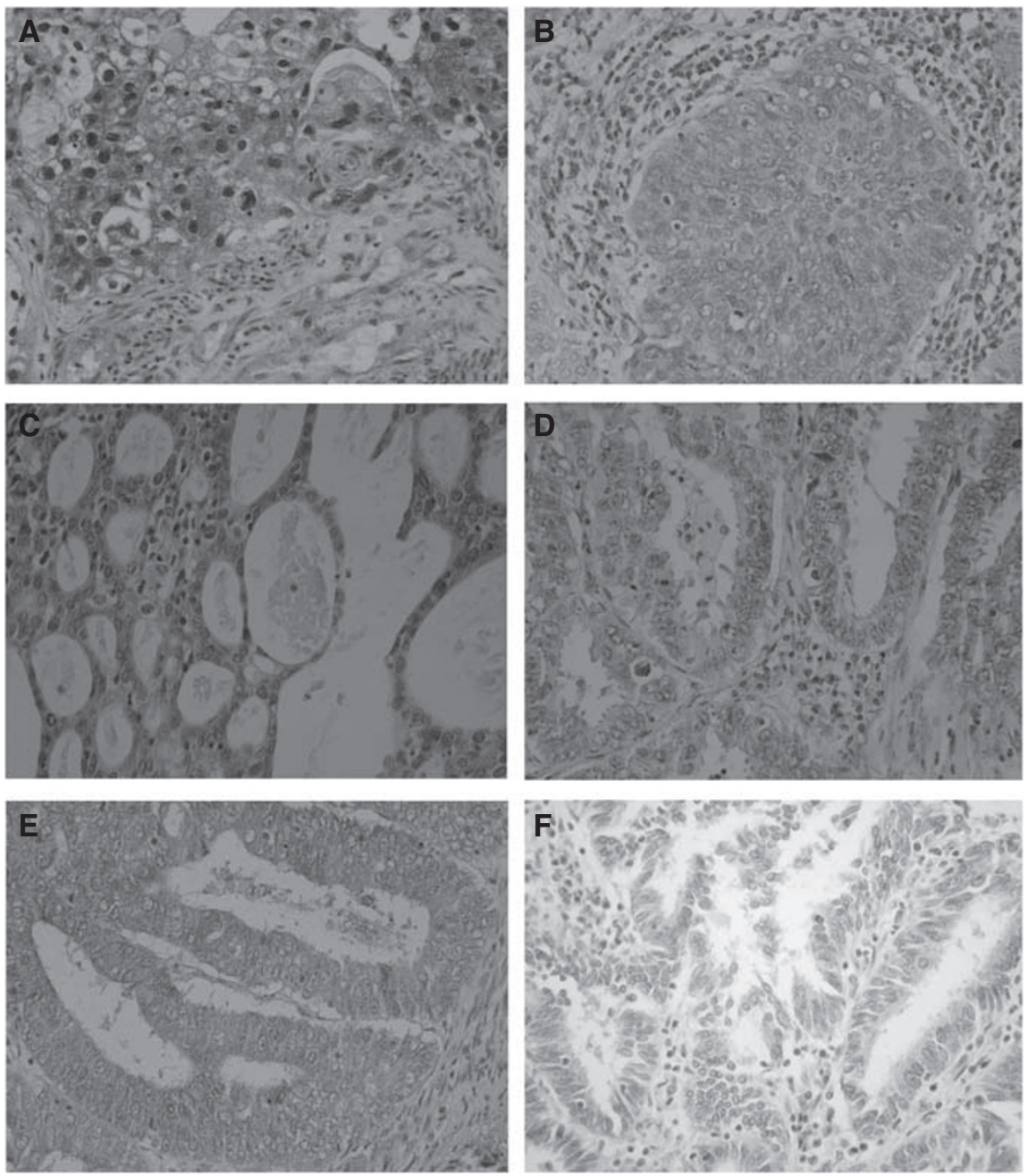

Figure 2 ATP-binding cassette superfamily F2 immunohistochemical staining in cervical and endometrial cancer. (A) ATP-binding cassette superfamily F2-positive cervical cancer (squamous cell carcinoma). (B) ATP-binding cassette superfamily F2-negative cervical cancer (squamous cell carcinoma). (C) ATP-binding cassette superfamily F2-positive cervical cancer (adenocarcinoma). (D) ATP-binding cassette superfamily F2-negative cervical cancer (adenocarcinoma). (E) ATP-binding cassette superfamily F2-positive endometrial cancer. (F) ATP-binding cassette superfamily F2-negative endometrial cancer. 
A

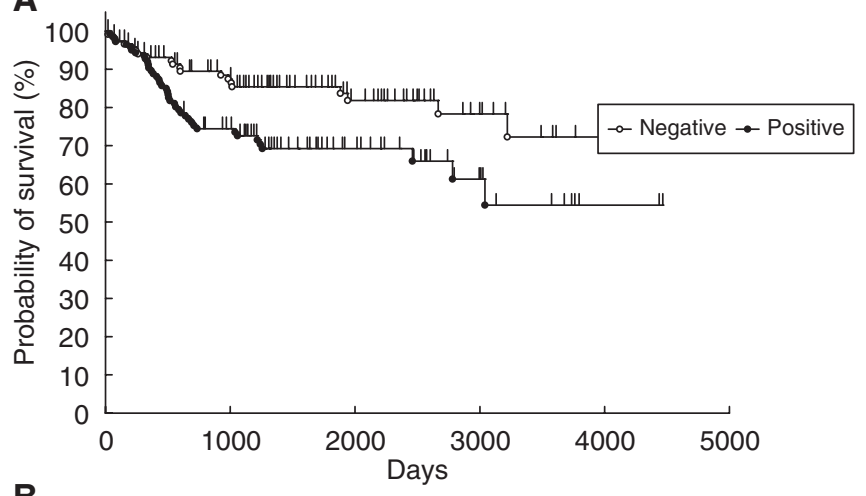

B

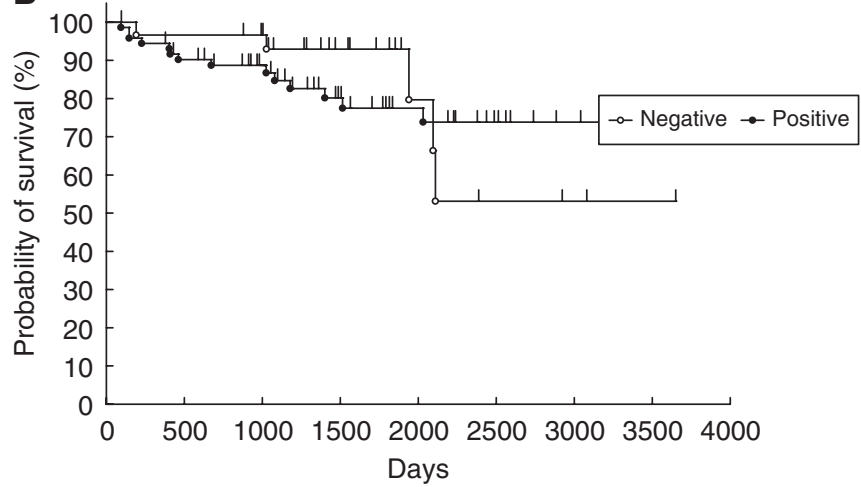

Figure 3 (A) Relationship between ABCF2 expression and $O S$ in cervical cancer. ATP-binding cassette superfamily F2-negative cases show longer OS than in ABCF2-positive cases $(P=0.0069)$. (B) Relationship between ABCF2 expression and the OS in endometrial cancer. ATPbinding cassette superfamily F2 expression and OS are not related $(P=0.67)$.

cervical cancer cases, 149 (55.8\%) were cytoplasmic ABCF2 positive. ATP-binding cassette superfamily F2 was more frequently expressed in advanced (stage III + IV) than in early (stage I + II) cases $(75.9$ vs $50.7 \%, P=0.001)$. However, there was no significant relationship between age, histologic type and ABCF2 expression (Table 1). Among endometrial cancer cases, 72 (69.9\%) were cytoplasmic ABCF2 positive. There was no association between age, clinical stage, histologic type, histologic grade, oestrogen receptor status and $\mathrm{ABCF} 2$ expression (Table 2). Representative ABCF2 staining is shown in Figure 2.

\section{Relationship between ABCF2 expression and overall survival (OS)}

The median follow-up period for cervical cancer patients was 1280 days (20-4679 days). Overall survival was significantly related to age and clinical stage but not to histologic type. The OS was longer in stage I+ II than in stage III + IV cases $(P<0.0001)$ and in younger than older cases $(P=0.0007)$. Twenty of 118 ABCF2 negative and 41 of 149 ABCF2-positive cases died. Overall survival of ABCF2 negative was longer than ABCF2-positive cases $(P=0.0069)$ (Figure 3A). Prognostic factors influencing survival were ABCF2 positivity (risk ratio $(\mathrm{rr})=1.437 ; P_{\mathrm{h}}=0.0063$ by proportional hazard test, $P_{1}=0.0069$ by log-rank and $P_{\mathrm{w}}=0.001$ by Wilcoxon test), old age $\left(\mathrm{rr}=1.550 ; P_{\mathrm{h}}=0.0008, P_{1}=0.0007\right.$ and $\left.P_{\mathrm{w}}=0.0015\right)$ and advanced stage $\left(\mathrm{rr}=2.577 ; \quad P_{\mathrm{h}}<0.0001\right.$, $P_{1}<0.0001$ and $P_{\mathrm{w}}<0.0001$ ) (Table 3). ATP-binding cassette superfamily F2 positivity and old age were independent significant prognostic factors by multivariate proportional hazard test $(P=0.0002)$. The rrs for negative ABCF2 and old age were 0.720
Table 3 Statistical analysis of prognostic factors for OS

\begin{tabular}{lccc}
\hline Variable & $\begin{array}{c}\text { Univariate } \\
\text { P-value }\end{array}$ & $\begin{array}{c}\text { Hazard } \\
\text { ratio }\end{array}$ & $\mathbf{9 5 \% ~ C l}$ \\
\hline Age & 0.0008 & 1.549 & $1.199-2.029$ \\
Histology & 0.17 & 1.242 & $0.904-1.651$ \\
Clinical stage & $<0.0001$ & 2.577 & $1.993-3.329$ \\
ABCF2 & 0.0063 & 0.696 & $0.527-0.904$ \\
\hline
\end{tabular}

Age: > median age, histology: non-squamous cell carcinoma. Clinical stage: III+IV ABCF2: negative. Hazard ratio refers to risk of death, with values < 1.0 indicating reduced risk. $\mathrm{Cl}=$ confidence interval.

(0.544-0.936; 95\% CI, $P=0.00137)$ and $1.510 \quad(1.167-1.978$, $P=0.0016)$, respectively.

For endometrial cancer cases the median follow up period was 1429 days (93-3675 days). Overall survival was longer in stage I + II disease than in stage III + IV cases $(P<0.0001)$. Endometrioid adenocarcinoma had better OS than non-endometrioid adenocarcinoma $(P=0.001)$. However, there was no relationship between $\mathrm{ABCF} 2$ expression and $\mathrm{OS}(P=0.67)$ (Figure $3 \mathrm{~B})$.

\section{DISCUSSION}

Recently, we reported that $\mathrm{ABCF} 2$ expression was related to prognosis in ovarian CCC and breast cancer. In ovarian CCC, ABCF2 expression was associated with chemoresistance and OS (Tsuda et al, 2005a, b; Ogawa et al, 2006), while in breast cancer, lack of ABCF2 expression was associated with increased diseasefree survival (Ogawa et al, 2006). ATP-binding cassette superfamily F2 is a member of the GCN20 subfamily of the ABC transporter superfamily (Vasquez de Aldana et al, 1995). Similar to other members of the ABC family, ABCF2 contains a pair of nucleotidebinding domains but it lacks a transmembrane domain (Allikmets et al, 1996; Kerr, 2004), suggesting that it is unlikely to function as a cell membrane transporter, as do other members of the $\mathrm{ABC}$ family. ATP-binding cassette superfamily F2 may be involved in translational control, antibiotic resistance and RNase L inhibition (Trope et al, 2005). Although the ABCF2 gene is amplified in a chemoresistant ovarian cancer cell line (t24/cDDp10) with chromosome gain at 7q34-36 (Yasui et al, 2005), its role in tumour biology remains to be established. In this study, we examined the relationship between ABCF2 expression, clinical factors and prognosis in cervical and endometrial cancer.

In cervical cancer, ABCF2 expression was higher in stages III and IV than stages I and II tumours but expression was not related to histology or age of the patients. The OS was longer in ABCF2negative than ABCF2-positive cases $(P=0.0069)$. In addition, ABCF2 positivity was shown to be a significant independent prognostic factor by multivariate proportional hazard test. In cervical cancer, squamous cell antigen (SCC) is thought to be a useful marker. Pretreatment SCC levels correlate with cellular differentiation, tumour stage and volume, lymph node status and blood vessel invasion (Reynolds et al, 2005). However, there are conflicting reports on the prognostic significance of pretreatment SCC measurements (Scambia et al, 1994; Gaarenstroom et al, 1995; Duk et al, 1996; Ngan et al, 1996; Bolger et al, 1997; Hong et al 1998). In addition, there are no useful markers in cervical adenocarcinoma. In this study, the $\mathrm{ABCF} 2$ positivity rate was $61 \%$ (25 of 41 ) in cervical non-squamous cell carcinoma and expression correlated with OS. ATP-binding cassette superfamily F2 may therefore be a useful biomarker in cervical cancer, although a larger study will be needed to confirm this conclusion. In contrast, $\mathrm{ABCF} 2$ expression was not related to OS and clinical factors such as age, stage, histologic type, histologic grade and oestrogen receptor status in endometrial cancer. Thus, the role of ABCF2 may differ according to tumour type. 
In ovarian cancer, $\mathrm{ABCF} 2$ protein expression was related with histologic types (significantly higher in clear-cell type compared with other histologic types) (Tsuda et al, 2005a; Nishimura et al, 2007). However, in cervical and endometrial cancer, its expression was not related with histologic types. In cervical cancer and clear cell types of ovarian cancer, ABCF2 expression was related with survival, however, in endometrial cancer and other histologic types of ovarian cancer, its expression was not related with survival (Tsuda et al, 2005b). The reason remains unclear. The role of $\mathrm{ABCF} 2$ protein may differ among histologic types or origin.

In conclusion, ABCF2 expression may be a useful prognostic marker in cervical cancer but its expression is not related to prognosis and clinical factors in endometrial cancer.

\section{ACKNOWLEDGEMENTS}

We are grateful to Dr Naoki Kawamura of Osaka City General Hospital for his critical review of the manuscript and to Asami Nagata and Nozomi Tsuji for their technical assistance. This study was supported by Grant-in-Aid for Scientific Research(C) (19591940) from the Ministry of Education, Science and Culture, Japan; Grant from Osaka City General Hospital.

\section{REFERENCES}

Allikmets R, Gerrard B, Hutchinson A, Dean M (1996) Characterization of the human $\mathrm{ABC}$ superfamily: isolation and mapping of 21 new genes using the expressed sequence tags database. Hum Mol Genet 5: $1649-1655$

Bolger BS, Dabbas M, Lopes A, Monaghan JM (1997) Prognostic value of preoperative squamous cell carcinoma antigen level in patients surgically treated for cervical carcinoma. Gynecol Oncol 65: 309-313

Duk JM, Groenier KH, de Bruijn HW, Hollema HW, ten Hoor KA, van der Zee AG, Aalders JG (1996) Pre-treatment serum squamous cell carcinoma antigen: a newly identified prognostic factor in early-stage cervical carcinoma. J Clin Oncol 14: 111-118

Gaarenstroom KN, Bonfrer JM, Kenter GG, Korse CM, Hart AA, Trimbos JB, Helmerhorst TJ (1995) Clinical value of pre-treatment serum Cyfra 21-1, tissue polypeptide antigen, and squamous cell carcinoma antigen levels in patients with cervical cancer. Cancer 76: 807-813

Gaffney DK, Haslam D, Tsodikov A, Hammond E, Seaman J, Holden J, Lee RJ, Zempolich K, Dodson M (2003) Epidermal growth factor receptor (EGFR) and vascular endothelial growth factor (VEGF) negatively affect overall survival in carcinoma of the cervix treated with radiotherapy. Int J Radiat Oncol Biol Phys 56: $922-928$

Hamel NW, Sebo TJ, Wilson TO, Keeney GL, Roche PC, Suman VJ, Hu TC, Podratz KC (1996) Prognostic value of p53 and proliferating cell nuclear antigen expression in endometrial carcinoma. Gynecol Oncol 62: $192-198$

Hong JH, Tsai CS, Chang JT, Wang CC, Lai CH, Lee SP, Tseng CJ, Chang TC, Tang SG (1998) The prognostic significance of pre- and posttreatment SCC levels in patients with squamous cell carcinoma of the cervix treated by radiotherapy. Int J Radiat Oncol Biol Phys 41: 823-830

Ioka A, Tsukuma H, Ajiki W, Oshima A (2003) Trends in uterine cancer incidence in Japan 1975-1998. Jpn J Clin Oncol 33: 645-646

Kerr ID (2004) Sequence analysis of twin ATP binding cassette proteins involved in translational control, antibiotic resistance, and ribonuclease L inhibition. Biochem Biophys Res Commun 315: 166-173

Koulos J, Wright TC, Follen MF, Silva E, Atkinson EN, Richart RM (1993) Relationships between cKiras mutations, HPV types and prognostic indicators in invasive endocervical adenocarcinomas. Gynecol Oncol 48: $364-369$

Lundgren C, Auer G, Frankendal B, Moberqer B, Nilsson B, Nordstrom B (2002) Nuclear DNA content, proliferative activity, and p53 expression related to clinical and histopathologic features in endometrial carcinoma. Int J Gynecol Cancer 12: $110-118$

Moreno-Bueno G, Hardisson D, Sanchez C, Sarrio D, Cassia R, GarciaRostan G, Prat J, Guo M, Herman JG, Matias-Guiu X, Esteller M, Palacios J (2002) Abnormalities of the APC/B-catenin pathway in endometrial cancer. Oncogene 21: $7981-7990$

Ngan HY, Cheung AN, Lauder IJ, Wong LC, Ma HK (1996) Prognostic significance of serum tumour markers in carcinoma of the cervix. Eur J Gynaecol Oncol 17: $512-517$

Nishimura S, Tsuda $\mathrm{H}$, Ito $\mathrm{K}$, Jobo $\mathrm{T}$, Yaegashi $\mathrm{N}$, Inoue $\mathrm{T}$, Sudo $\mathrm{T}$, Berkowitz RS, Mok SC (2007) Differential expression of ABCF2 protein among different histologic types of epithelial ovarian cancer and in clear cell adenocarcinomas of different organs. Human Pathol 38: 134-139
Ogawa Y, Tsuda H, Hai E, Tsuji N, Yamagata S, Tokunaga S, Nakazawa K, Tamamori Y, Ogawa M, Shimizu S, Inoue T, Nishiguchi Y (2006) Clinical role of ABCF2 expression in breast cancer. Anticancer Res 26: 1809-1814 Randall M, Michael H, Vermorken J, Stehman F (2005) Uterine cervix. In Principles and practice of gynecologic oncology. Hoskins WJ, Young RC, Markman M, Perez CA, Barakat R, Randall M (eds) 4th edn, pp 743-822. Lippincott, Williams \& Wilkins: USA

Reynolds K, Menon U, Jacobs I (2005) Development and Identification of Tumour Markers. In Principles and practice of gynecologic oncology. Hoskins WJ, Young RC, Markman M, Perez CA, Barakat R, Randall M (eds) 4th edn, pp 157-178. Lippincott, Williams \& Wilkins: USA

Riou G, Barrois M, Le MG, George M, Le Doussal V, Haie C (1988) c-myc proto-oncogene expression and prognosis in early carcinoma of the uterine cervix. Lancet 2: 761-763

Sagae S, Kuzumaki N, Hisada T, Mugikura Y, Kudo R, Hashimoto M (1989) ras oncogene expression and prognosis of invasive squamous cell carcinomas of the uterine cervix. Cancer 63: 1577-1582

Scambia G, Benedetti Panici P, Foti E, Amoroso M, Salerno G, Ferrandina G, Battaglia F, Greggi S, De Gaetano A, Puglia G (1994) Squamous cell carcinoma antigen: prognostic significance and role in the monitoring of neoadjuvant chemotherapy response in cervical cancer. J Clin Oncol 12: $2309-2316$

Stehman FB, Perez CA, Kurman RJ, Thigpen JT (2000) Uterine Cervix. In Principles and practice of Gynecologic Oncology. Hoskins WJ, Perez CA and Young RC (eds) 3rd edn, pp p841-p918. Lippincott, Williams \& Wilkins: Philadelphia, PA, USA

The Japan Cancer Surveillance Research Group (in press) Cancer incidence and incidence rate in Japan in 2000: estimated based on data from 11 population-based cancer registries. Jpn J Clin Oncol 36: 643-648, 2006

Trope CG, Alektiar KM, Sabbatini PJ (2005) Corpus Uteri: Epithelial tumours. In Principles and practice of gynecologic oncology. Hoskins WJ, Young RC, Markman M, Perez CA, Barakat R, Randall M (eds) 4th edn, pp 823-872. Lippincott, Williams \& Wilkins: USA

Tsang RW, Wong CS, Fyles AW, Levin W, Manchul LA, Milosevic M, Chapman W, Li YO, Pintillie M (1995) Tumour proliferation and apoptosis in human uterine cervix carcinoma II: correlations with clinical outcome. Radiother Oncol 50: 93-101

Tsuda H, Ito YM, Ito K, Yaegashi N, Nishimura S, Birrer MJ, Ohashi Y, Hashiguchi Y, Berkowitz RS, Mok SC (2005a) Prognostic value of ABCF2 in ovarian clear cell adenocarcinoma. Proc ASCO 23: 463(5037)

Tsuda H, Ito YM, Ohashi Y, Wong KK, Hashiguchi Y, Welch WR, Berkowitz RS, Birrer MJ, Mok SC (2005b) Identification of overexpression and amplification of ABCF2 in clear cell ovarian adenocarcinomas by cDNA microarray analysies. Clin Cancer Res 11: 6880-6888

Vasquez de Aldana CR, Marton MJ, Hinnebusch AG (1995) GCN20, a novel ATP binding cassette protein, and GCN1 reside in a complex that mediates activation of the eIF- $\alpha$ kinase GCN2 in amino acid-starved cells. EMBO J 14: 3184-3199

Yasui K, Mihara S, Zhao C, Okamoto H, Saito-Ohara F, Tomida A, Funato T, Yokomizo A, Naito S, Imoto I, Tsuruo T, Inazawa J (2005) Alteration in copy numbers of genes as a mechanism for acquired drug resistance. Cancer Res 64: 1403-1410 